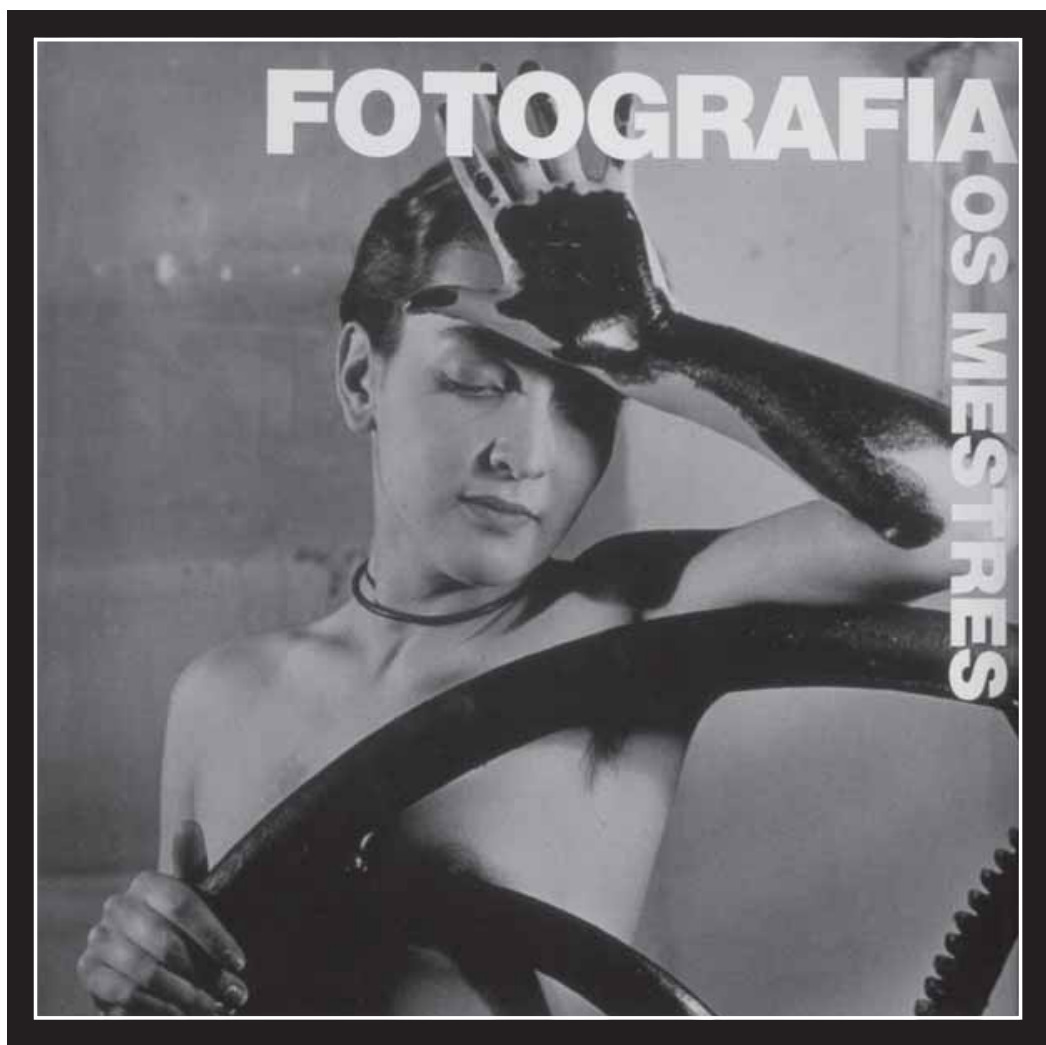

FOTOGRAFIA: Os mestres. Milão: Scala/logos, 2010. 507 p.

Espanhol, inglês, italiano, português

DOI $10.5433 / 1984-7939.2011 v 7 n 10 p 215$

disarsos fotogááicos, Londrina, v7, n.10, p.215-279, jan/jun. 2011 


\title{
Um panorama da história da fotografia por imagens de grandes mestres
}

An overview of the history of photography through great masters' images

\author{
Anderson Coelho*
}

Henry Talbot, Lewis Hine, Eugène Atget, Cartier-Bresson, Robert Doisneau, Alberto Korda e Robert Mapplethorpe são alguns dos nomes que compõem o livro Fotografia: os mestres, publicado pelas editoras Scala e Logos, ambas de Milão (Itália), em 2010. Com 507 páginas e primorosa edição, a obra oferece um panorama de dezenas dos mais relevantes nomes da fotografia mundial, de seu surgimento e primeiros experimentos às tendências contemporâneas.

Dividido em sete capítulos, o livro aborda cronologicamente os momentos mais significativos para história da fotografia: os primeiros experimentos atrelados ao seu nascimento e à criação de estilos, passando pelos experimentalismos e novas possibilidades nos primeiros decênios do século XX. Ainda no século XX, trata da aliança da fotografia com as artes nas propostas das novas vanguardas e dos protagonistas dos anos 30. Aborda o impacto e a repercussão da Segunda Guerra Mundial na fotografia, a maturação do fazer fotográfico nos anos 40 e 50 , as rupturas de regras e conceitos e a atribuição do status de arte dos anos 60 até os dias atuais.

Fotografia: os mestres é um referencial importante para o conhecimento e compreensão da história da fotografia, pois reúne e analisa trabalhos de autores das mais diferenciadas formações técnicas e tendências. A edição, em grande formato, com diagramação arejada e papel de boa qualidade, se torna um fator relevante para a apreciação das fotografias pelo leitor.

\footnotetext{
* Anderson Coelho é fotógrafo. Mestrando em Comunicação pela Universidade Estadual de Londrina. Bolsista da Capes - Coordenação de Aperfeiçoamento de Pessoal de Ensino Superior.
} 
Em seus quase dois séculos de existência, a fotografia galgou importantes degraus e hoje se encontra em elevado patamar de magnitude. Ela ainda é muito jovem se a comparada às demais artes, mas sua dimensão é descomunal quando inserida na história da humanidade. O ser humano sempre teve necessidade de criar maneiras de eternizar suas memórias. A possibilidade de imortalizar-se no mundo, ou o constante medo do esquecimento, fez com que a civilização criasse a oralidade, a pintura e a escrita. No século XIX, com a invenção da fotografia, o mundo passou por abruptas mudanças nas formas de expressão e sentido. Ela é uma experiência que até hoje provoca revisões de paradigmas. A fotografia transcendeu o status inicial de "espelho do real” e alçou uma fronteira maior, a de possibilidade de transformação e ressignificação de realidades.

Mas essa evolução criou um grande embate sobre aceitar ou não essa "técnica de registro" como arte. Com o passar dos anos, novas possibilidades de pensar a fotografia foram ganhando espaço, o que resultou no nascimento de novos paradigmas e incontáveis e incessantes indagações. Até que ponto pode-se crer que a fotografia não pertença ao terreno do real? Ao fazermos um registro já estamos ficcionalizando a realidade? Esses questionamentos são reelaborados cada vez mais, em razão das constantes evoluções tecnológicas que assombram a curta história da fotografia. A cada dia surgem novas possibilidades de criação de imagens, as quais não são apropriadas unicamente pelos artistas, mas por todos que queiram registrar, reescrever ou remontar o real. A fotografia, atualmente, é considerada um elemento intrínseco de nossa cultura. Seu impacto é tão forte que, em alguns casos, tem o poder de nortear o real.

As páginas de Fotografia: os mestres mostram claramente a grande relevância do legado imagético que temos. No primeiro capítulo, o livro aborda vários fotógrafos do início da fotografia. Trata de Félix Nadar e os retratos com fortes semelhanças com pictorialismo. Num momento em que a fotografia ainda dava seus primeiros passos, mostra os estudos sobre os movimentos de cavalos e pessoas e as fotografias revolucionárias 
de Eadweard James Muybridge. No encerramento do século XIX, destaca a importância das fotografias de denúncia social de Jacob August Riis, que retratou - e denunciou - as péssimas condições de vida dos imigrantes favelados nova-iorquinos, notadamente os de origem latina.

No segundo capítulo, aborda os passos iniciais das então novas possibilidades da fotografia. Neste sentido, explora o uso do imaginário para compor retratos, de Adolf de Meyer, e a fotografia do cotidiano londrino, com Paul Martin, que buscava encontrar o espontâneo dos fotografados por meio de uma câmera fotográfica escondida em uma maleta. Da mesma época, expõe o trabalho de Lewis Hine e sua forte documentação sobre a exploração da mão-de-obra infantil nas fábricas dos Estados Unidos.

Tratando das primeiras décadas do século XX, o terceiro capítulo exibe o intenso trabalho de registro da Paris antiga - e seus personagens característicos - tomado por Eugène Atget; a efervescência de Nova Iorque, registrada por Alfred Stieglitz; imagens arquitetônicas do período; os experimentalismos artísticos do húngaro Moholy-Nagy, um dos símbolos da fotografia da Bahaus; o abstracionismo de Man Ray; e as conhecidas fotografias de rua de André Kertész.

O quarto capítulo, ambientando nos anos 30, traz o fotojornalismo político de Erich Salomon, considerado o pai do moderno fotojornalismo; o fotodocumentarismo de Dorothea Lange, que andou grande parte dos Estados Unidos a serviço da FSA - Farm Security Administration durante a grande depressão, registrando a dura condição dos que moravam nas afastadas zonas rurais do centro-oeste americano; e o olhar metódico e certeiro de Henri Cartier-Bresson, com seu rígido ritual de observação e captura do conhecido "instante decisivo".

Durante os anos 40 e 50, a Segunda Guerra Mundial - e suas repercussões - marcou profundamente a fotografia, não somente em evolução de equipamentos, mas em revisão de paradigmas. No quinto capítulo, as fotografias impactantes de conflitos, a conquista do Reichstag alemão, de Jewgeni Chaldej, e a destruição de cidades durante os combates, de Herbert Hensky, dão lugar à fotografia humanista de Robert 
Doisneau, com imagens que transmitem a poeticidade no cotidiano do povo francês. Este capítulo também abre espaço para o mestre Ansel Adams e sua precisão na composição de paisagens.

No sexto capítulo, que trata dos anos 50 e 60, é marcante a fotografia de Alberto Korda, fotógrafo que registrou a revolução cubana de Fidel Castro e autor da mais conhecida imagem de Che Guevara. Também ganha destaque os fabulosos retratos de Cecil Beaton e os espontâneos e sinceros registros da Londres do pós-guerra de Henry Grant.

Finalmente, no sétimo e último capítulo, que trata dos anos 60 aos dias atuais, encontramos o panorama do modo de vida americano, de Lee Friedlander, a harmonia e sensibilidade de Elliott Erwitt, e os trabalhos de Andy Warhol, protagonista da pop art americana. Vários outros mestres da fotografia, de todos os períodos abrangidos pelos sete capítulos, são lembrados e homenageados.

Por sua abrangência e consistência, Fotografia: os mestres é uma obra imprescindível, pois reúne os mais expressivos nomes da fotografia mundial. Sua leitura é recomendada para fotógrafos profissionais e amadores, academias e escolas de fotografia. Trata-se de um completo passeio imagético pelo trajeto histórico de como foi pensada e construída a fotografia, dos primeiros experimentos de Niépce às tendências contemporâneas, como David LaChappelle. 